\title{
Research on the Construction of Campus Culture in Higher Vocational Colleges Based on the Perspective of Educational Innovation
}

\author{
Jiaji Gao ${ }^{1, a}$ and Yan Yan ${ }^{2, b *}$ \\ ${ }^{1}$ Dalian Ocean University, Dalian, Liaoning, 116000, China \\ ${ }^{2}$ Dalian Ocean University, Dalian, Liaoning, 116000, China \\ a64127957@qq.com, b911533633@qq.com
}

Keywords: Higher vocational; Campus culture; Innovation

\begin{abstract}
The study of campus culture construction in colleges and universities plays a vital role and influence on the overall construction of the school, and the important part is the higher vocational college which is a powerful push for the study of campus culture in colleges and universities. Colleges and universities are the most innovative youth groups. The higher vocational college, as an important component and a practical group, is bound to have a good impetus to the innovation of the campus culture. This paper deeply studies the cultural construction of higher vocational colleges with the goal of promoting the construction of campus culture in higher vocational colleges based on the innovation of campus culture.
\end{abstract}

\section{Introduction}

The contents of the research into campus culture construction in higher vocational schools are quite extensive, including the research into the spiritual, material, institutional and behavioral aspects. Broadly speaking, the research covers the status quo of campus culture, problems existing in campus culture and resolutions to solve these problems. What's more, the research is also associated with how to facilitate the overall development of university campus culture through studying campus culture in higher vocational school. In this way, we can reserve the characteristics of campus culture in higher vocational school. What's more, based on this research, we can give impetus to teaching research and scientific research and developing the second class of students.

After looking up the literature review concerning campus culture construction in higher vocational school and also combing the relative research material at home and abroad and also through the field inspection, and launching academic seminars, we acquire excellent experience and put the experience we obtain into effect in real earnest. Besides, we should combine closely theory with practice, stick to practical questions existing in campus culture as the guide, strengthen the research related to campus culture construction in higher vocational school and also improve continuously the theoretical system of campus culture construction.

\section{The Sketch of Campus Culture in Higher Vocational School}

The Definition of Theory Concerned with Campus Culture in Higher Vocation School. The overall campus culture construction in higher vocational school in China equals to the construction of learning spirit and school spirit that takes the spiritual, material, institutional, behavioral level as the starting point. Higher vocational schools should form the dense academic atmosphere and the elegant aesthetic atmosphere, engage in manifold extracurricular activities, build beautiful school environment, achieve the effect encouraging students to work hard and to learn broadly, and to persevere putting what has learned into use. Developing democratic and scientific value, creating positive environment for students' own opinions, and fostering a harmonious and civilized ideology, all will be conducive to the recruitment and teaching of higher vocational school. Making ideology and condition more harmonious is propitious to the formation of the recruitment, teaching and school culture and also to making higher vocational school becoming exemplary school with specialization. 
Figuring out the Meaning of Campus Culture. Higher vocational school is currently characterized by its own unique symbol, centralizing culture, quality and management and so on. To say it specifically, campus culture in higher vocational school is the reflection of social change and it has its own features and also has a positive influence on the current society. Schools should keep pace with the times, conform to the trend of development of the times, and build positive energy campus culture that can represent advanced cultural orientation, thus making teachers and students grow up in such an elegant campus culture, facilitating the formation of their positive ideas and also promoting the humanistic quality to a new level, which is also propitious to guide the present talented persons construction. All of this can contribute to the mental and physical development of higher-level practically talented persons through education, and also to promoting their positive engaging in social practice.

Establishing the Theoretical Pattern of Campus Culture Construction. Develop the model establishment of theoretical study of campus culture construction: we can use four models to analyze the campus culture construction, which includes spirit, material, behavior and also institution model. In this process, it is also necessary to centralize the spiritual culture, base the material culture, take the institution as normalization and also spread through behavioral culture.

Main Content of the Research into Campus Culture. The basic function of material culture: the characteristic of material base of a school is also the specific demonstration of spiritual culture carrying spiritual civilization.

The core function of spiritual culture: spiritual culture is the soul of all culture. It leads material and institutional culture and shepherds the promotion of shaping of humanistic environment and atmosphere. In the whole process of teaching, value and relative social psychology have gradually formed, manifested in campus spirit.

The normalizing function of behavioral culture: the current value, the behavioral rules and the overall situation, the compositional pattern related to school, the interactive model among persons and the relative culture formed in teacher's and student s' learning and working and living are all the specific exhibition of school spirit, learning spirit and teaching spirit in school, which are also the condensation of school spirit, and also are of great benefit to promoting the development of positive energy of campus culture.

Guaranteed function of institutional culture: in the whole construction process, school needs the institutional guarantee, such as moral standards of teacher and students and relative norms, which is shown in every perspectives of the school management.

Practical Function of Campus Culture Construction. Campus culture has the guiding function and the centripetal force, capable of achieving the condensing function. What's more, it has the facilitative and stable function and demonstrative function. Culture is the carrier of spirit. Cultural richness of a school is achieved through a long term accumulation and through the incessant improvement of campus culture construction. Excellent campus culture serves as the spiritual leading, making all teachers and students move forward to a more fantastic direction, which shows up as the spiritual existence and incessantly supports and leads all the teachers and students to make some accomplishments.

The Analysis of Progressiveness in Campus Culture in Higher Vocational School. Advanced culture can promote the further development of campus culture in higher vocational school. Today's world culture is the combination of diversity and unity. With the economic openness brought by the overall cultural variation, Chinese cultural structure is in a diversified situation currently. For example, people advocate combining humanism with science and democracy. Present economic openness and development facilitates the incessant variation and modification, thus forming diversified and abundant cultural structure. With the formation of the idea of amalgamation which involves humanism, freedom and especially legal idea, some excellent foreign thoughts and the pursuits of higher thought bring teachers and students more abundant contents and forms, which promote the campus culture construction continuously and enrich the system of campus culture.

The current campus culture construction in university is hereditary. The important feature is developing the practical education. Newman, an educator from Britain, pointed out that "college 
education is to teach students how to be fit in with others, to stand in others' position to consider things, to pass on their own thought to others, to influence others, to achieve mutual understanding, to achieve mutual tolerance, to get along well with others and to find something in common, which are all the object college education pursue."

The ever-changing society exerts a great influence on campus culture construction. Culture keeps pace with the times. Social cultural environment changes and culture also changes to some extent. Campus cultural variation in higher vocational school is influenced by the overall politics, economy and culture in the advanced age.

The Research on Campus Culture Construction Pattern with Characteristics. Advance the industry- university-research development and develop moral education and demonstrate the practical features. Higher vocational schools need to combine the current employment outlook with marketing needs, locate themselves suitably and reasonably, modify their teaching thought, continuously improve their specialization and specialized teaching system, and also enhance their teaching quality.

Cultivating practical and technical talents is the key to earning the fierce employed competition and also the important method to improve the comprehensively competitive power.

Establishing the characterized and abundant department and ministry culture based on diversion. All departments and ministries are the basic unit, just like all kinds of cells of higher vocational school in China. They are so diversified that they form the splendidly and colorfully comprehensive campus culture.

Expand tradition, propagate the main melody and form brand characteristics. All universities, in the process of developing the activities of campus culture construction, inherit traditions and expand glowing sedimentary deposits and brew marvelous brands. The university should apply the developmental history of university and the accumulation of each given historical juncture into the ongoing campus culture construction and continuously innovate and integrate, thus forming the campus culture leading brand with excellent characteristics.

To be thoroughly tempered and accumulated and preserving. All the ideological constructions are almost the same, which are permanent and systematical jobs. Likewise, campus culture construction cannot be done at one stroke. The specifically ideological and cultural features possessed by students in higher vocational school are created by teachers and students' positive engagement and perseverance and gradual accumulation.

\section{Problems Existing in Campus Culture Construction in Higher Vocational School}

The foundation of cultural construction is vulnerable, lacking the completely cultural instruction and also the theoretical guidance. With the development of society and economy, higher vocational schools achieve their own development. Higher vocational education is a kind of newly developing educational type. There is no mature theoretical guidance, and the vulnerable basement and lower starting point are common problems faced by mostly higher vocational schools. The situation of current campus institutional culture in higher vocational school can be vividly described as a matter of trial and error.

Higher vocational education has been in an imitating situation for higher education, lacking the requirement for its own characteristics. Mostly higher vocational schools follow the teaching models and relative institutions used in senior high schools, and take the school as the center rather than the curriculum, thus diverging from the current teaching situation, which is unable to meet their development need.

Cultural construction lacks specialization and has no definite objective. The developing objective which cultivates practical talented persons with high professional qualification is the ultimate goal for the current campus culture construction. They simply copy campus culture in higher education. As a result, they turn themselves into clone or mini regular institution of higher education, thus losing their characteristics.

Campus culture construction in higher vocational school is to pursue short term effect, not permanent development. For the purpose of enhancing their social recognition, many higher 
vocational schools construct suddenly the characterized projects within short time for coping with educational evaluation temporarily. Enthusiasm put on these characterized projects will fade away with the end of the assessment. And finally, characteristics become no characterized at all.

\section{The Exploration of Path for Campus Culture Construction}

Good school spirit and learning spirit are the appearance and image. However, the current construction of school spirit in higher vocational school is far from satisfied. Campus culture construction in higher vocational construction is not as good as the construction in regular institutions of higher education. We can know how to establish good school spirit in higher vocational school from the following paths: The first is to unify the recognition of teachers and students. Ideology goes first. The construction of school spirit should be enhanced. The second is to manage jointly, that is, the school, teachers and students all together bear the responsibility of constructing the school spirit. The third is to be realistic and pragmatic and exhibit earnest attitude towards it, intrigue teachers and students positively obey and maintain the school spirit. The last is to take advantage of hand-written newspaper and solicit articles and all kind of other forms, intensifying school spirit.

The school spiritual culture permeates into everywhere in school. Through relative researches and practical activities, we should take campus culture construction as an important content for cultivating students and make it integrate into everywhere in school and entrenching it in school really.

Accelerating the institutional development of campus culture construction. The result of research will be changed directly into inner managing model and be applied in the school, promoting the establishment and consolidation of campus cultural institution.

Developing diversified campus cultural practices. Cultural quality education should be embedded in campus culture and art activities, thus students can acquire self-education and cultivation in the Campus Culture and Art festival and students' comprehensive qualification can be promoted.

Take campus culture construction as a gripper and form continuously consequent experience. In the activities of campus culture construction, the schools' influence is widened, good social and economic benefits are obtained, and a new way suitable for the construction of higher vocational colleges is explored.

Externalization of the inner cultural deposits in all higher vocational schools equals to spiritual and cultural features. It has distinctive characteristics and individualities. Higher vocational school is a part of higher education. However, unlike producing a product requested to have a unanimous standard, as a type of higher education, higher vocational school has its own characteristics. Meanwhile, higher vocational school is an important part in vocational education. Because of the difference of educational types, campus culture will be different. Further research into how to distinguish them will be the studying direction in the future. Research methods are still to be explored further for resolving the problems in a more suitable way, which is still to be explored. How to deal with the relationship between campus culture construction in higher vocational school and marketing economy still needs to be studied.

\section{Acknowledgements}

Fund Project: The Scientific Research Project of the Liaoning Education Department(w201604).

\section{References}

[1] xi jinping, young people should conscientiously practice the core socialist values -- speech at the symposium of teachers and students of Peking University [R], May 5, 2014.

[2] xue Ming, the reasons for the formation of higher vocational students' values and the countermeasures of education [J],education and occupation, no. 33 (total 709) p68-70. 
[3] liu congli, values education plays a role in improving the quality of students in higher vocational colleges [J],professional education, p142-143.

[4] Lu Aijun $\mathrm{Xu}$ Hongfei, research on the training of Higher Vocational Students' values, [J], Journal of Beijing Vocational College of Agriculture, Vol. twenty-eighth, third issue P104-108

[5] jiang qiuming,the development and analysis report of yunnan professional education [Z].

[6] Peng L, Xiaoping Z. Social Stratification and Cooperative Behavior in Spatial Prisoners' Dilemma Games [J]. PLOS ONE, 2015, 10(7): e0131005. 